\title{
Multivariate analysis of exercise parameters measured during the training of Thoroughbred racehorses
}

\author{
J. P. Valette', P. H. Heiles ${ }^{2}$ and R. Wolter ${ }^{3}$ \\ ${ }^{1}$ INRA, E.A. Biomécanique du Cheval, Ecole Nationale Vétérinaire, Maisons-Alfort, France \\ ${ }^{2}$ Garde Republicaine, Régiment de cavalerie, Service vétérinaire, Paris, France \\ ${ }^{3}$ Unité de Nutrition, Ecole Nationale Vétérinaire, Maisons-Alfort, France
}

\begin{abstract}
Summary
The aim of this study was to measure exercise parameters in horses which had performed standardised exercise tests and to verify their use as predictive indexes of horse fitness. Eight horses were tested, on the same track with the same rider. The test consisted of a warm-up followed by three 3 min-steps one cantering and two galloping. The test was followed by a recovery period. The heart rate was recorded during the entire test. Blood samples were taken during the 2 min rest periods following each step, and after the recovery period for the measurement of lactate concentrations. Exercise parameters were defined by the relationship between lactate concentrations, heart rate and velocity.

Results were treated by the multivariate discriminant analysis procedure which indicates that the cardiovascular system seems to be improved during the protocol and that the efficiency score and the cardiac recovery index seem to be good indicators of potential speed.
\end{abstract}

Keywords: $\quad$ exercise test, fitness indicators, discriminant analysis, efficiency score

\begin{abstract}
Diskriminanzanalyse von Leistungsparametern bei Galopprennpferden anhand von Messungen während des Trainings
Das Ziel dieser Studie war, Leistungsparameter von Pferden bei standardisierten Leistungstests zu messen und ihren Voraussagewert für die Fitness der Pferde zu überprüfen.

Es wurden acht Pferde, fünf Hengste und drei Stuten im Alter von vier bis sechs Jahren, je fünfmal im Abstand von je fünfzehn Tagen getestet. Die Tiere befanden sich seit zwei Monaten im Training für Jagdrennen. Die Tests fanden immer auf derselben Bahn statt und es kam immer derselbe Reiter zum Einsatz.

Der Leistungstest bestand aus einer Aufwärmphase, worauf eine Stufe im Canter bei $450 \mathrm{~m} / \mathrm{min}$ und zwei Stufen im Galopp bei $600 \mathrm{~m} / \mathrm{min}$ und $750 \mathrm{~m} / \mathrm{min}$ folgten. Die Dauer jeder Stufe betrug drei Minuten, zwischen den Stufen wurde eine zweiminütige Pause eingelegt.

Während des gesamten Tests wurde die Herzfrequenz aufgezeichnet, Blutproben zur Messung von Laktat und Hämatokrit wurden in den Pausen nach jeder Stufe und am Ende des Tests nach einer Erholungsphase entnommen. Anhand der Beziehung zwischen Laktatkonzentration, Herzfrequenz und Geschwindigkeit wurden Leistungsparameter definiert.

Mit den Ergebnissen wurde eine Diskriminanzanalyse durchgeführt. Daraus ging hervor, daß in 95 \% der Fälle die Pferde dem Test zugeordnet werden konnten, in dem die zugrunde liegenden Leistungsparameter bestimmt worden waren. Es erfolgte eine positive Anpassung des Herz-Kreislauf-Systems über den Versuchszeitraum. Auch die anaerobe Kapazität verbesserte sich. Anhand des Effektivitätskoeffizienten, der Beziehung zwischen den Parametern Herzfrequenz und Laufgeschwindigkeit, und der Erholungsfähigkeit des Herz-Kreislauf-Systems ist eine Beurteilung von Geschwindigkeit und Ausdauerleistungsvermögen der Pferde auch ohne die Entnahme von Blutproben möglich.
\end{abstract}

Schlüsselwörter: Leistungstest, Indikatoren für Fitness, Diskriminanzanalyse, Effektivitätskoeffizient

\section{Introduction}

Physiological data from Thoroughbred racehorses is now well defined by the use of treadmills which allow the investigation of many functions (cardiovascular, respiratory and locomotor systems). It is sometimes difficult to apply these study protocols to the track situation, although this has already been done with Standardbred (Wilson et al., 1983; Demonceau and Auvinet, 1992; Dubreucq et al., 1995) and Thoroughbred (Foreman et al., 1990; Harkins et al., 1993; Lindner and von Witt$k e, 1993)$ racehorses. The aim of this study was to measure exercise parameters in horses which repeatedly performed standardised exercise tests over a period of 3 months, to examine the correlations between them with a multivariate analysis (Valette et al., 1991) and to verify their use as predictive indexes of horse fitness.

\section{Materials and methods}

Horses

Eight healthy horses ( 5 stallions and 3 mares) were used in this study. They were 4 to 6 years old and were trained for steeplechase races for 2 months. They were fed a concentrate diet twice daily at levels which provided nutrient requirements for maintenance and work.

\section{Exercise test}

Each horse was tested 5 times, every 15 days between November and February, on the same track (1800 meters) with the same rider. The atmospheric conditions were similar during the 5 tests with temperatures between 6 and $9^{\circ} \mathrm{C}$ and in dry condi- 
tions. The test consisted of a 30 min warm-up walking and trotting at $250 \mathrm{~m} / \mathrm{min}$ followed by three $3 \mathrm{~min}$-steps cantering (450 $\mathrm{m} / \mathrm{min}$ ) and galloping (600 and $750 \mathrm{~m} / \mathrm{min}$ respectively). The test was followed by a recovery period; 10 min trotting at $250 \mathrm{~m} / \mathrm{min}$ and then 5 min walking. All the exercise tests were performed under acceple conditions of care and welfare for horses.

The heart rate $(H R)$ was recorded (Baumann $B H L$ 5000) during the entire test and the data were averaged during the last minute. Blood samples were taken during the 2 min rest periods following each step and after the recovery period for the measurement of haematocrit (PCV) and lactate concentrations (LA) after deproteinisation in perchloric acid. Blood samples were taken at rest (for clinical examination), 3 hours later for CK (creatine kinase) and 24 hours later for AST (aspartate aminotransferase) which are indicators of muscle damage.

Definition of the derived exercise parameters

For each horse, 12 parameters were calculated and constituted quantitative variables.
The linear relationship between HR and velocity $(M)$ was described by V200; the slope of the relationship (HRs); EC, an efficiency score which is the velocity during the last step of the test divided by the heart rate (Ivers, 1989) and CRI (cardiac recovery index) which is the $\mathrm{HR}$ at the end of the test divided by the HR after 1 min of recovery (Valette and Sablon, 1992). The relationship between LA and velocity was studied using an exponential model (Demonceau et al., 1991; Valette et al., 1991);

$$
L A=\exp \left(\text { Acurv }^{*} V+b\right)+c
$$

where Acurv is a coefficient of curvilinearity and $b$ and $c$ are constant values and analysed with a solver program (Eureka, Borland international). The lactate dependant change was described by the following criteria: VLa4; Acurv; Vs, the velocity at which blood lactate dramatically increased and LAT, the corresponding blood lactate threshold. In addition, other pa-

Tab. 1: Exercise parameters obtained after 5 standardized tests on 8 horses

\begin{tabular}{|c|c|c|c|c|c|c|c|c|}
\hline & Test 1 & Test 2 & Test 3 & Test 4 & Test 5 & Mean & F value & Proba \\
\hline & & & & & & & $4 / 35 \mathrm{df}$ & $\%$ \\
\hline \multirow[t]{2}{*}{ V200 (m/mn) } & 714 & 722 & 702 & 721 & 734 & 719 & 0.20 & ns \\
\hline & 41 & 73 & 103 & 59 & 59 & 71 & & \\
\hline \multirow[t]{2}{*}{ HRs } & 21.45 & 25.55 & 19.15 & 16.30 & 19.75 & 20.45 & 1.65 & ns \\
\hline & 5.10 & 5.85 & 11.80 & 4.40 & 5.65 & 7.70 & & \\
\hline \multirow[t]{2}{*}{ HR4 (beats/mn) } & 185 & 186 & 189 & 187 & 182 & 186 & 0.45 & ns \\
\hline & 5 & 15 & 14 & 4 & 7 & 11 & & \\
\hline \multirow[t]{2}{*}{ EC } & 3.50 & 3.57 & 3.50 & 3.57 & 3.66 & 3.56 & 0.55 & ns \\
\hline & 0.21 & 0.30 & 0.30 & 0.18 & 0.19 & 0.25 & & \\
\hline \multirow[t]{2}{*}{ CRI } & 1.71 & 1.65 & 1.60 & 1.60 & 1.68 & 1.65 & 1.20 & ns \\
\hline & 0.13 & 0.16 & 0.10 & 0.07 & 0.12 & 0.13 & & \\
\hline \multirow[t]{2}{*}{ SL } & 87.3 & 97.8 & 114.9 & 110.6 & 85.4 & 99.2 & 2.55 & ns \\
\hline & 32.1 & 18.1 & 19.6 & 12.0 & 24.1 & 25.2 & & \\
\hline \multirow[t]{2}{*}{ LRI } & 1.35 & 1.36 & 1.86 & 1.33 & 1.69 & 1.52 & 2.00 & ns \\
\hline & 0.61 & 0.18 & 0.47 & 0.42 & 0.49 & 0.50 & & \\
\hline \multirow[t]{2}{*}{ Vla4 (m/mn) } & 674 & 706 & 666 & 672 & 650 & 674 & 1.95 & ns \\
\hline & 36 & 18 & 55 & 26 & 47 & 43 & & \\
\hline \multirow[t]{2}{*}{ Vs $(m / m n)$} & 638 & 668 & 636 & 631 & 625 & 640 & 1.25 & ns \\
\hline & 35 & 12 & 62 & 25 & 39 & 41 & & \\
\hline \multirow[t]{2}{*}{ Acurv } & 1.15 & 1.94 & 1.71 & 1.49 & 1.09 & 1.48 & 2.55 & ns \\
\hline & 0.28 & 0.61 & 0.85 & 0.67 & 0.41 & 0.68 & & \\
\hline \multirow[t]{2}{*}{ LAT (mmol/l) } & 2.88 & 2.48 & 2.92 & 2.57 & 3.17 & 2.80 & 1.75 & ns \\
\hline & 0.31 & 0.47 & 0.63 & 0.56 & 0.72 & 0.61 & & \\
\hline \multirow[t]{2}{*}{ PCV (\%) } & 50.65 & 52.40 & 56.50 & 54.65 & 52.70 & 53.40 & 4.40 & 0.60 \\
\hline & 5.05 & 2.75 & 3.20 & 2.00 & 1.85 & 3.50 & & \\
\hline
\end{tabular}


rameters were measured: HR4, which is the HR at VLa4; LRI (lactate recovery index) which is the $L A$ at the end of the test divided by the LA after 15 min of recovery; and SL, a lactate index which is the velocity divided by the blood lactate concentration, during the last step. Acurv, Vs and LAT may be indicators of the onset of blood lactate accumulation (Valette et al., 1989).

\section{Statistical analysis}

In order to study the improvement of the fitness of horses during the training period, data were ranked in 5 groups (the 5 exercise tests). Data were treated by the multivariate discriminant analysis procedure (DA) which takes into account all the tre of the graph are not clearly explained by the first and second components which represented 64.3 and $17.3 \%$ respectively of the total variance.

\section{Discussion}

Analysis of variance indicated that none of the variables except for PCV (Tab. 1) was improved with time in response to the 5 tests. The first component included the parameters CRI, HRs, PCV and SL while the second component was a contrast of VLa4, VS, Acurv, LAT and EC. V200, HR4 and $\mathrm{LRI}$ were on the two components

The position of test 1 , situated closed to the intersection of axes 1 and 2 indicated that horses were not well prepared for

Tab. 2: Correlation coefficients between exercise parameters (38 df)

\begin{tabular}{|c|c|c|c|c|c|c|c|c|}
\hline & V200 & HRs & HR4 & EC & CRI & SL & VLa4 & Acurv \\
\hline HRs & $-0.58^{\circ 00}$ & & & & & & & \\
\hline HR4 & $-0.41^{\circ 0}$ & & & & & & & \\
\hline EC & $0.91^{000}$ & $-0.61^{000}$ & $-0.36^{\circ}$ & & & & & \\
\hline SL & & & & & $0,34^{\circ}$ & & & \\
\hline LRI & & & & & & $0,43^{\circ 00}$ & & \\
\hline VLa4 & & & $0.33^{\circ}$ & $0,42^{\circ \circ}$ & $0,36^{\circ}$ & $0,57^{000}$ & & \\
\hline Vs & $0.33^{\circ}$ & & $0.40^{\circ}$ & $0,47^{000}$ & $0,39^{\circ}$ & $0,59^{\circ 00}$ & $0.94^{000}$ & \\
\hline LAT & & & & & & & $-0.34^{\circ}$ & $-0.79^{\circ 00}$ \\
\hline PCV & & $-0.33^{\circ}$ & & $0,42^{\circ \circ}$ & & $0,42^{\circ \circ}$ & & \\
\hline
\end{tabular}

information given by the 12 quantitative variables (Valette et al., 1992). This statistical method compared the 5 groups by determining a set of new uncorrelated variables (1st, 2nd and 3rd components) defined by a linear combination of the variables with the maximum within-group variance. This analysis also provides correlation coefficients between all the variables, means (SD) and a 1-way analysis of variance.

\section{Results}

All horses performed the tests without showing any signs of exhaustion, plasma concentrations of CK and AST remained within the normal range. Table 1 indicates the means and SD obtained after the tests. Horses finished the tests with a mean $\mathrm{HR}$ value of 212 beats/min and a mean LA value of 9.2 $\mathrm{mmol} / \mathrm{l}$. The mean $\mathrm{V} 200$ was $719 \mathrm{~m} / \mathrm{min}(12 \mathrm{~m} / \mathrm{s})$ and the mean VLa4 value was $674 \mathrm{~m} / \mathrm{min}(11.2 \mathrm{~m} / \mathrm{s})$. There were good correlations (Tab. 2) between V200 and EC (0.91) and between VLa4 and Vs (0.94) which gave the same type of information. The lactate threshold parameters Acurv and LAT were negatively correlated $(-0.79)$. We observed no correlation between V200 and VLa4, nor between EC and CRI. EC and SL were not correlated but were correlated with VLa4 and $V$ s. Figure 1 shows the location of the centres of gravity of the 5 groups on axes 1 and 2 of the DA procedure. The closer the parameters are to the periphery, the more correlated they are. Parameters or groups situated close to the cen-

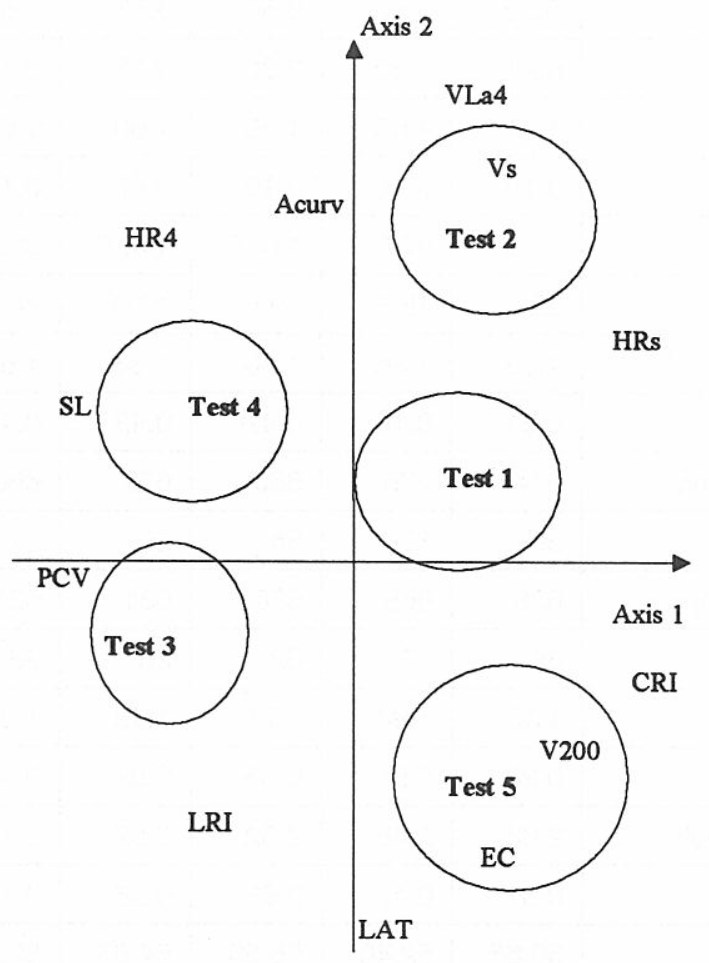

Fig. 1: Location of the centres of gravity of the 5 tests on axes 1 and 2 of the DA procedure (exercise parameters and tests are defined in the text) 
races at the beginning of the study. During the protocol, aerobic capacity was improved as noted by increases, firstly in VLa4 and Vs during tests 2 and 3 and then in oxygen transport capacity or PCV. The cardiovascular system was improved during the protocol as noted by the position of Test 5 on the component defined by V200, CRI and EC. Test 5 was characterised by decreases in VLa4 and Vs values and also by a lower value for Acurv and a higher value for LAT, indicating an improvement in anaerobic capacity (Valette et al., 1989). The DA procedure also calculated the probability of misclassification of a horse in another group (another test) by taking into account all the exercise parameter values. It was found that $95 \%$ of the values were correctly assigned to the group they were initially assigned to.

Thorougbbred racehorses have higher V200 and VLa4 values than have Standardbred horses (Dubreucq et al., 1995) which may be explained in part by the lower energetic cost of gallop. The efficiency score was closely correlated with V200, an indicator of anaerobic fitness. The efficiency score and the cardiac recovery index are easy to measure during a training schedule when heart rate can be recorded but blood samples are not available. They are not correlated and therefore give complementary information. They seem to be good indicators of potential speed and of the aptitude to sustain prolonged work, when examined at velocities where HR is over 200 beats/min.

\section{References}

Demonceau, T., Valette, J. P., Wolter, R., Barrey, E., Galloux, P. and Auvinet, B. (1991): Modélisation de la relation lactate-vitesse chez le cheval de sport en fonction de la spécificité de l'entraînement. In: CR 17ème journée d'étude CEREOPA. pp 99-107.

Demonceau, T. and Auvinet, B. (1992): Test d'effort de terrain pour trotteurs à l'entraînement: réalisation pratique et premiers résultats. In: CR 18ème journée d'étude CEREOPA. pp 120-132.

Dubreucq, C., Chatard, J. C., Couroucé, A. and Auvinet, B. (1995): Reproducibility of a standardised exercise test for Standardbred trotters under field conditions. Equine Vet J Suppl 18, 108-112.

Foreman, J. H., Bayly, W. M., Grant, B. D. and Gollnick, P. D. (1990): Standardized exercise test and daily heart responses in Thoroughbreds undergoing conventional race training and detraining. Am J Vet Res 51, 914-920.

Harkins, J. D., Beadle, R. E. and Kamerling, S. G. (1993): The correlation of running ability and physiological variables in Thoroughbred racehorses. Equine Vet J 25, 53-60.

Ivers, T. (1989): The joy of culling. Equine Sportsmedicine News $8,110-111$.

Lindner, A. and von Wittke, P. (1993): Standardization of exercise tests under field conditions to evaluate physiological adaptations to training. In: Proc Ass Equine Sports Med Fallbrook, California. p 43.
Valette, J. P., Barrey, E., Garbasi, C. and Wolter, R. (1989): Estimation du seuil anaérobie chez le poney. Ann Zootech 38, 229-236.

Valette, J. P., Barrey, E. and Wolter, R. (1991): Multivariate analysis of exercise parameters measured during an incremental treadmill test. In: Equine Exercise Physiology 3. Eds: S. G. B. Persson, A. Lindholm and L. B. Jeffcott. ICEEP publications, Davis, California. pp 337-342.

Valette, J. P., Barrey, E., Auvinet, B., Galloux, P. and Wolter, R. (1992): Comparison of track and treadmill tests in saddle horses: a preliminary report. Ann Zootech 41, 129-135.

Valette, J. P. and Sablon, D. (1992): Test de détection de l'aptitude physique chez le jeune pur-sang arabe de course. EquAthlon 4, 7-9.

Wilson, R. G., Isler, R. B. and Thornton, J. R. (1983): Heart rate, lactic acid production and speed during a standardised exercise test in Standardbred horses. In : Equine Exercise Physiology. Eds : D. H. Snow, S. G. B. Persson and R. J. Rose. Granta Editions, Cambridge. pp 487-496.

\section{Acknowledgements}

We thank Andrew Ponter, PhD ENV Alfort, for english revision.
J. P. Valette

INRA

E.A. Biomécanique du Cheval

Ecole Nationale Vétérinaire

7 avenue du Général-de-Gaulle

F-94704 Maisons-Alfort

France

P. H. Heiles

Garde Republicaine

Régiment de cavalerie

Service vétérinaire

18 boulevard Henri IV

F-75181 Paris

France

\section{R. Wolter}

Unité de Nutrition

Ecole Nationale Vétérinaire

7 avenue du Général-de-Gaulle

F-94704 Maisons-Alfort

France 